\title{
BONE IN OSTEOPETROSIS
}

\author{
G. Ramkumar ${ }^{1}$, V. L. Narayanan², R. Kalanithi ${ }^{3}$
}

\section{HOW TO CITE THIS ARTICLE:}

G. Ramkumar, V. L. Narayanan, R. Kalanithi. "Bone in Osteopetrosis". Journal of Evolution of Medical and Dental Sciences 2014; Vol. 3, Issue 16, April 21; Page: 4276-4281, DOI: 10.14260/jemds/2014/2431

ABSTRACT: Osteopetrosis, a generalized developmental bone disease due to genetic disturbances, characterized by failure of bone re sorption and continuous bone formation making the bone hard, dense and brittle. Bones of intramembranous ossification and enchondrial ossification are affected genetically and symmetrically. During the process of disease the excess bone formation obliterates the cranial foramina and presses the optic, auditory and facial nerves resulting in defective vision, impaired hearing and facial paralysis. The bone formation in osteopetrosis affects bone marrow function leading to severe anemia and deficient of blood cells. The bone devoid of blood supply due to compression of blood vessels by excess formation of bone are prone to osteomyelitic changes with suppuration and pathological fracture if exposed to infection. Though the condition is chronic progressive, it produces changes leading to fatal condition, it should be studied thoroughly by everyone and hence this article presents a classical case of osteopetrosis with detailed description and discussion for the benefit of readers.

KEYWORDS: Albers- Schonberg disease, Marble bone disease, Dense bone, Pathological fracture.

INTRODUCTION: Bone is a tissue, bones are organs. Bones develop both by intramembranous ossification and enchondrial ossification. Re sorption of old bone by osteoclasts and apposition of new bone by osteoblasts are continuous process of remodeling of bone. ${ }^{1}$ The amount of resorbed bone is replaced equally with the same amount of new bone maintaining the physiological equilibrium of bone. The disturbances of remodelling of bone by various causes produce dystrophic changes of bone and these dystrophies are called osteodystrophies. Osteopetrosis is one of the osteodystrophies of bone.

Osteopetrosis is also called Albers - Schonberg disease as he was the first person to describe osteopetrosis in 1904. It is also called marble bone disease. This rare genetic disease is associated with four genes TCIRG1, CICN7, OSTM1, PLEKHM1. ${ }^{2}$ Excess bone formation with increased density of the skeleton associated with failure of resorption is the main feature of this disease and it occurs symmetrically.

The types of osteopetrosis includes a malignant form of congenital type in young individuals as autosomal recessive type, a benign form particularly in adults as autosomal dominant type, renal tubular acidosis causing osteopetrosis as autosomal recessive type. ${ }^{3}$ But patients exposed to bisphosphonates may also develop a condition like osteopetrosis as bisphosphonates incorporate with apatite crystals of bone making the bone difficult to resorb. ${ }^{4}$

The failure of bone re sorption in osteopetrosis is due to the deficiency in function and differentiation of osteoclasts, the multinucleated giant cells which are responsible for bone re sorption. The exact nature of pathological changes of osteoclasts is not known. Failure of re sorption of bone by defective osteoclasts and continuous formation of bone makes the bone thick, hard, dense and fragile. Excess bone formation causes vascular, neural, bone marrow and bone structure changes. The serious complication is the disturbances of hemopoetic system ${ }^{5}$. In this article a female patient 


\section{CASE REPORT}

suffering from osteopetrosis is presented and various changes in the bones are described in detail and discussed.

CASE REPORT: Female patient of 28 years old had a complaint of a bulge and pain in the clavicular region and the pain is referred to shoulder region for the past 9 months. The pain was severe initially and progressively reduced on medical treatment. She also complained of stunted growth and dental defects. No history of any trauma and family history is nil relevant.

General examination of patient revealed that the patient was short and stout, her vital parameters like BP, pulse, and cardiac beats were normal. Her vision, hearing, speech and taste were normal, but she was slightly anaemic and had mild breathlessness on exertion. Other functions of different organ systems were normal and no hepatosplenomegaly. Patient was sent for blood routine investigation of blood and urine. Urine showed no presence of sugar, blood examination showed that the patient had $6.8 \mathrm{~g} \%$ hemoglobin, serum calcium and phosphorus were normal but slight elevation of alkaline phosphatase was present.

Local examination, on inspection the skull is slightly large with mild frontal bossing, thickening of facial soft tissues with a bulge bilaterally in the maxillary sinus region were observed. Missing teeth, malformed teeth with dental caries were seen in the mouth. A localized bony swelling with irregular borders and raised surface was seen in the middle of right side clavicle, the skin covering the swelling is normal and intact, movements of clavicle and shoulder were also normal. Upper extremities, fingers of hands, lower extremities and fingers of feet appeared normal and movements were not restricted.

On palpation, skull bone is slightly thick, irregular and rough in certain areas. Bone in body of maxilla bilaterally is thick and surface is irregular. The bone in right clavicle is enlarged, hard, and tender with irregular surface. Skin over the area is pinchable. Patient had mild pain on right clavicular and shoulder region on palpation. Palpation of bones in the extremities and fingers were normal except a bony prominence nodular in character was seen in the middle of the shaft of tibia.

Radiographic findings: Skull shows areas of more opacity in different parts. The trabecular bone pattern and marrow spaces were seen in normal bone but not seen in the areas of more opacity. Diplod in the skull is partially obliterated with much radiopacity. More radiopacity was seen in the base of the skull and the base of the skull appears to be enlarged. Strange observation is the more radiopacity in the body of maxilla obliterating the maxillary sinus both sides. Excess opacity also seen in the lateral wall of the nose. Missing teeth and malformed teeth were seen in the mandible radiographically and the vertical width of the mandible appears to be less with more opacity. In the right clavicular region more irregular opacity was seen with absence of trabecular bony pattern.

Cervical spine appears more radiopaque. Long bones of upper extremities and finger bones showed more radiopaque areas, with loss of bone structure. Long bones of lower extremities also showed uniform radiopacity. Radiopacity was seen not only in the epiphyseal and metaphyseal region but also in the subperiosteal areas in the long bones in the shaft. More radiopacity with loss of trabecular structure were seen in the long bones in metaphyses which merges with the epiphyses. Where ever there was radiopacity it was difficult to distinguish between marrow bone and spongy bone. Marrow spaces were very much narrowed in the tubular bones.

In conclusion, the history, clinical and radiographic findings suggest that the condition is osteopetrosis. 
DISCUSSION: As the patient was not young and the changes were not aggressive, the condition is not a malignant osteopetrosis. Osteopetrosis due to kidney disease and bisphosphonates were ruled out as there were no relevant history.3.4 As the condition developed in the adult and was progressive in nature without serious complications, the patient described in this article was suffering from benign osteopetrosis of autosomal dominant type.

The thickening of bone in the skull and the bulge of bone in the maxillary region, clavicular region and the middle of tibia are excess bone formation as proved by the more radiopacity. The excess bone formation in the clavicle associated with mild pain may be due to irregular and excess bone formation due to healing process of previous mild fracture of the clavicle. ${ }^{6}$ In the same way the excess bone formation in the middle of shaft of tibia is also due to excess bone formation of healing process of previous mild fracture. The obliteration of maxillary sinus is due to excess bone formation in the maxilla. Malformed teeth and unerupted teeth in the jaw were due to compression and alteration of tooth germ due to excess formation of bone during the development of tooth. ${ }^{7}$ More opacity of spine in cervical vertebrae is due to more bone formation.

More radiopacity seen in the bones of upper, lower extremities and fingers are due to excess bone formation. Absence of trabecular pattern, absence of marrow spaces and narrow marrow spaces in long bones, failure of differentiation of cortical bone and spongy bone seen in the radiographs are classical features of osteopetrosis. ${ }^{8}$ The patient clinically had anemia and the anemia may be due to bone marrow alteration, though excess bone formation were noted these excess bone formation has not produced any deformity and pathological fracture in the present case. As the patient has good vision, proper hearing and no facial changes, obliteration of foramina in the cranial structure was not found in this patient. ${ }^{9}$

In osteopetrosis only osteoclastic dysfunction plays a role as bone is not resorbed and no disturbances in the metabolic activities of calcium and phosphorus. The defective structural changes are due to defective bone formation which is dense. Osteoclastic dysfunction is only partial and not total.

COMPLICATIONS OF OSTEOPETROSIS: Osteopetrosis is a chronic progressive disease, in which bone structure is hard, dense and brittle in nature. So fracture of the bone can develop due to mild trauma. The reason for fracture is that the bone is not fully calcified. 6

Though there is no visible deformity, areas of bone bulge can be seen and felt as localized bone formation in osteopetrosis.

Excess bone formation affects the development and eruption of teeth, malformed teeth and absence of teeth can occur in the mouth and the patient can find difficulty in chewing food. Deficient of calcification in the teeth causes dental caries.

Continuous bone deposition, compress and obliterate the blood vessels, wherever this compression occurs the blood supply to bone is lost, bone loses its viability, prone for infection to develop osteomyelitis.

Osteomyelitis in osteopetrosis produces bone thickening, bone pain, pus formation, inflammatory swelling, sinus formation and sequestrum formation and ultimately pathological fracture. Patient suffers from this disease continuously. 
As there is lack of blood supply and deficient of blood cells to deal the reparative process in osteomyelitis, healing process of osteomyelitis in osteopetrosis is very much inhibited and patient suffers from the disease for a long time due to unhealing of the osteomyelitic changes. ${ }^{10}$

When the long bones are fractured and exposed to infection in osteopetrosis, osteomyelitis can develop, but this is very rare. Commonly osteomyelitis in osteopetrosis develops in mandible following the infection in a tooth extracted wound. ${ }^{10}$

Excess bone formation in the foramina of cranial structures causes pressure of optic, auditory and facial nerve resulting in blindness, deafness and facial paralysis.

Excess bone formation affects the bone marrow function and blood formation and blood cells formations are affected.

The patient will develop hemopoetic dysfunction developing severe anemia leading to death. As a compensatory mechanism in the disturbances of hemopoetic system, the spleen will be enlarged in osteopetrosis.

CONCLUSION: A case of benign autosomal dominant osteopetrosis is presented and a detailed description and bone changes have been discussed. Facts and truth explained in this article would be a basis for reader, scientists and students to think further for proper analysis and management. It requires a detailed genetic study to correct defective osteoclasts and make a proper re sorption of bone to maintain the physiological remodeling of bone and prevent any further complication.

\section{BIBLIOGRAPHY:}

1. Greenspan A. Sclerosing bone dysplasias - a target site appraisal. Skeletal Radiol 20:562-583, 1991.

2. Frattini A, Vezzoni P, Villa A, Sobacchi C. The dissection of human autosomal recessive oeteopetrosis identifies an osteoclast - poor form due to RANKL deficiency. Cell Cycle 2007; 6: 3027-33.

3. Horton WA et al. Osteopetrosis: Further heterogenecity. J Pediatr 97:580-585, 1980.

4. Whyte MP, Wenkert D, Clements KL, McAlister WH, Mumm S. Bisphosphonate-induced osteopetrosis. N Engl J Med 2003; 349(5):457-63.

5. Nevile BW, Damm DD, Allen CM, Bouquot JE. Bone pathology. In: Oral and Maxillofacial pathology. $2^{\text {nd }}$ ed. China: Saunders; 2002. p. 533-87.

6. Robert B Duthie, George Bentley. MERCER'S Orthopedic Surgery, 9th ed. Jaypee; 2003.p. 271-4.

7. Bollerslev J. Osteopetrosis: A genetic and epidemiological study. Clin Genet 31:86-90, 1987

8. Johnston CC et al. Osteopetrosis: A clinical. Genetic, metabolic and morphologic study of the dominantly inherited benign form. Medicine 47:149-167, 1968.

9. Hoyt CS, Billson F. Visual loss in osteopetrosis. Am J Dis Child 133:955-958, 1973.

10. Batra P, Shah N. Recalcitrant osteomyelitis following tooth extraction in a case of malignant osteopetrosis. Int Dent J. 2004;54: 418-23. 


\section{CASE REPORT}
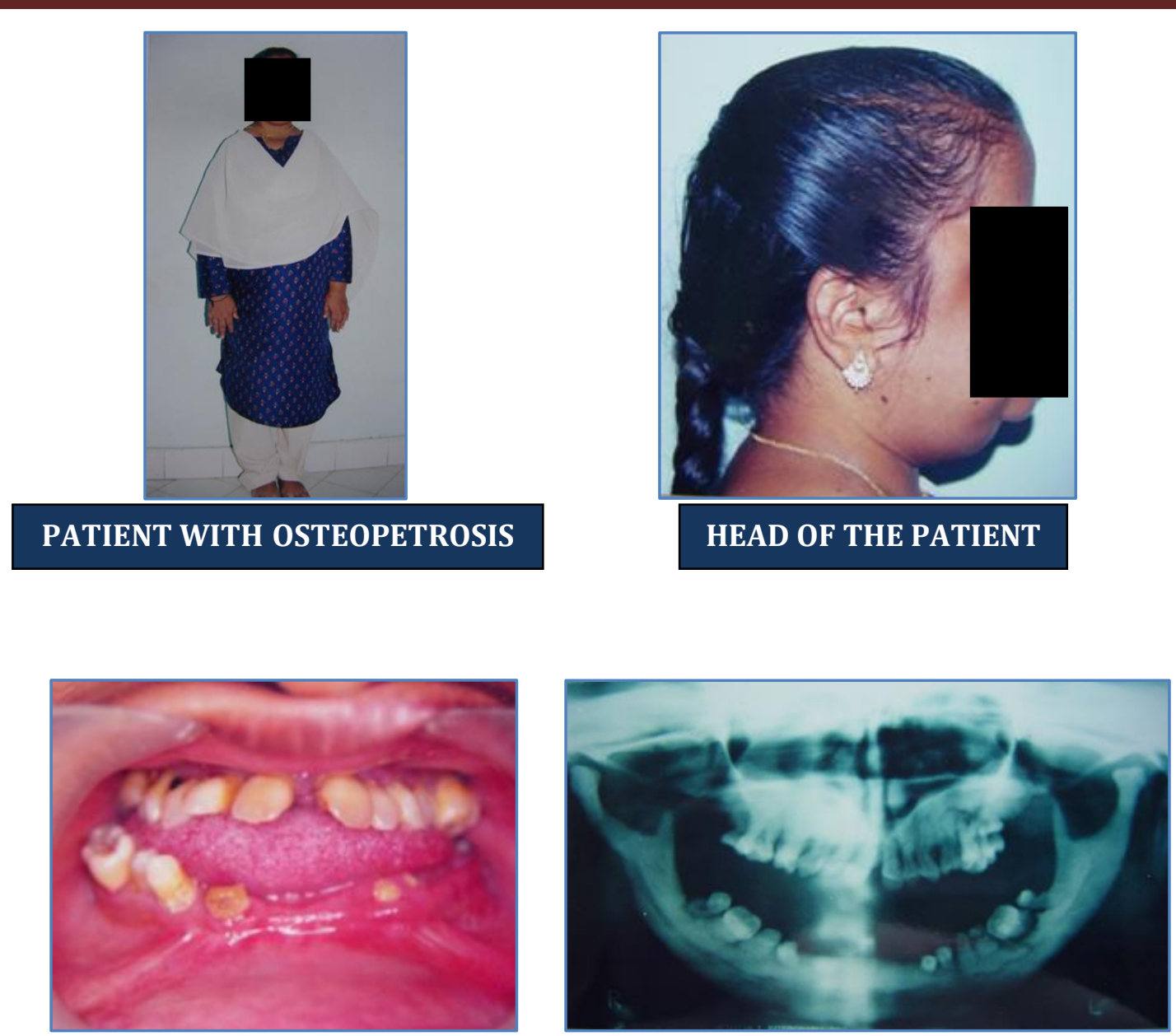

UNERUPTED MALFORMED, CARIOUS TEETH

TEETH AND JAWS IN PANORAMIC RADIOGRAPH
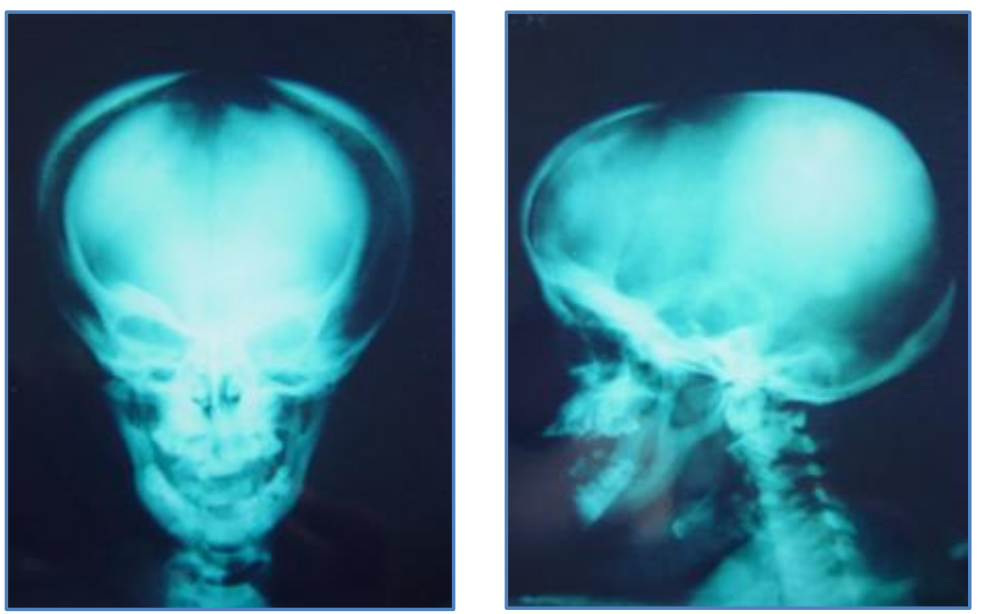

MORE RADIOPACITY IN SKULL BONES, WIDENED BASE OF THE SKULL 


\section{CASE REPORT}

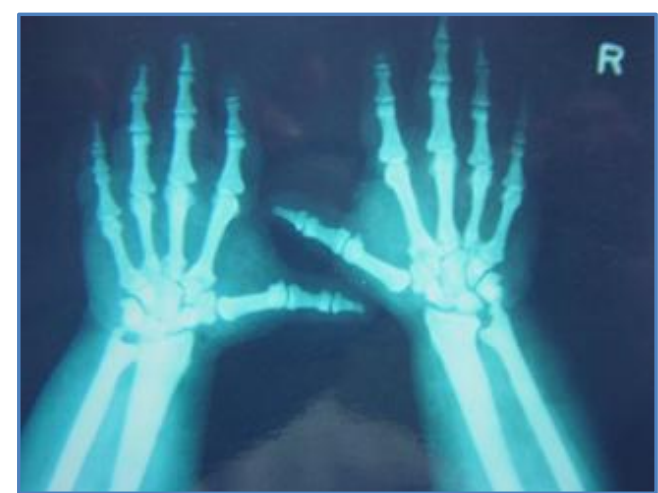

RADIOPACITY OF BONES IN HANDS

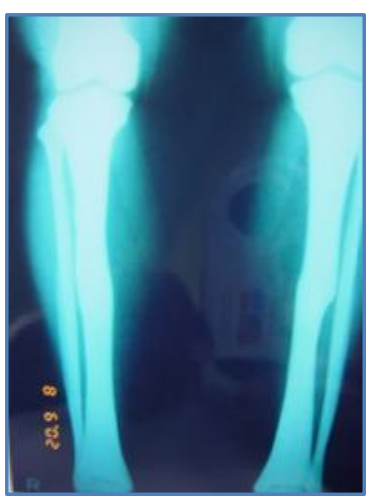

MORE RADIOPACITY OF BONES IN LEGS, BULGE IN THE SHAFT OF TIBIA

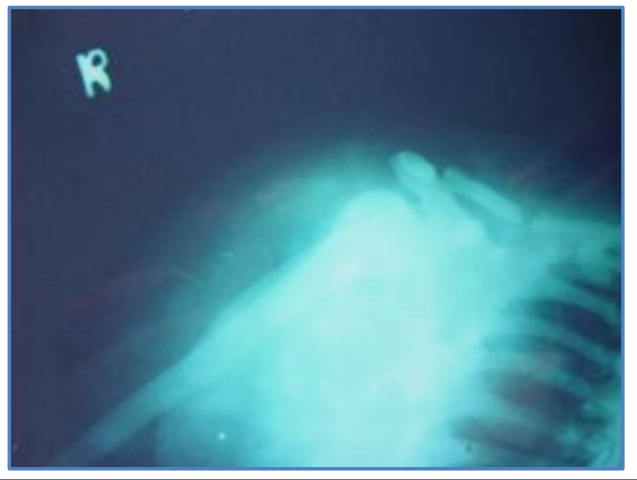

MORE BONE FORMATION IN SCAPULA

$\&$ CLAVICLE, SUSPECTED FRACTURE \& UNION WITH THICK BONE

\section{AUTHORS:}

1. G. Ramkumar

2. V. L. Narayanan

3. R. Kalanithi

\section{PARTICULARS OF CONTRIBUTORS:}

1. Associate Professor, Department of Orthopaedics, Saveetha Medical College, Chennai.

2. Assistant Professor, Department of Orthopaedics, Saveetha Medical College, Chennai.

3. Senior Resident, Department of Orthopaedics, Saveetha Medical College, Chennai.

NAME ADDRESS EMAIL ID OF THE

\section{CORRESPONDING AUTHOR:}

Dr. G. Ramkumar, \#AH 94, $4^{\text {th }}$ Street,

Annanagar, Chennai- 40

E-mail: kg.ramkumar@yahoo.com

Date of Submission: 22/03/2014.

Date of Peer Review: 24/03/2014.

Date of Acceptance: 29/03/2014.

Date of Publishing: 18/04/2014. 